\title{
Sound Insulation of Floors: A New Composite with a Resilient Layer of Recycled Polymer
}

\author{
Aline Zini ${ }^{1}$, Letícia K. Zuchetto ${ }^{2}$, Maria Fernanda de O. Nunes ${ }^{3}$, Ana M. C. Grisa ${ }^{1}$, Daniel T. Pagnussat ${ }^{3}$ and \\ Mara Zeni ${ }^{1}$ \\ 1. Laboratory of Materials Chemistry Research, University of Caxias do Sul, Caxias do Sul RS 95070-560, Brazil \\ 2. Institute of Technology for Civil Construction, University of Vale do Rio dos Sinos, São Leopoldo RS 93022-750, Brazil \\ 3. Laboratory of Constructive Technology, University of Caxias do Sul, Caxias do Sul RS 95010-550, Brasil
}

\begin{abstract}
PU (polyurethane) integral skin and PVC (polyvinyl chloride) are polymeric materials which have favorable physical characteristics to reduce the impact noise when applied to floor systems. In civil construction, floating floors systems are composed of two layers above the slab: a resilient layer and, above this, a rigid layer of cement matrix that works as a subfloor. This research aims to evaluate the incorporation of PVC and PU skin waste in the resilient layer of the floating floor, for impact noise insulation. It was conducted physical, mechanical and morphological tests in the composite, as SEM (scanning electron microscopy), determination of compressive creep, and impact noise test to evaluate the absorption capacity of the floor system over time. Furthermore, experimental results were compared with theoretical studies. These correlations may assist in understanding the behavior of impact noise damping and its relation to the size of the samples.
\end{abstract}

Key words: Floor system, impact noise insulation, recycled polymer.

\section{Introduction}

The floor slab is the structural element most often requested by impact noise sounds. The way to reduce these sounds transmitted by the building structure is to break the rigid connection by which radiates the mechanical stimulus of the impact between solid elements. Thus, the change of the impact surface, the use of an elastic cutting, or the insertion of a resilient material interposed between the rigid floor covering and the structural slab, are efficient solutions often adopted.

Materials as polymers in fiber form or elastomers, cork or textile materials are examples of resilient materials which may be placed beneath the rigid floor covering, composing therefore the floating layer for damping the initial mechanical impact on a floor system. These materials damp the impact energy

Corresponding author: Maria Fernanda de O. Nunes, Dr., associate professor, research fields: building acoustics, building performance and polymeric materials. through deformation by compression in the upper contact surface and transmit the reduced vibrational response through the lower contact layer.

In this context, the construction industry is a huge consumer of products whose environmental impact can be minimized by recycling, especially recycling of polymeric materials $[1,2]$. More specifically, the use of such waste is an alternative that has been studied for the improvement of impact sound insulation [3,4].

With a view to sustainability, recycling and reprocessing polymers have been shown to be economically viable in obtaining composites that have the same, or superior properties of pure materials, as well as being a solution found to decrease the accumulation of polymer waste in the environment.

Among the polymers most widely used, one that can be highlighted is the PU skin (polyurethane integral skin) and the PVC (polyvinyl chloride), which have wide application in various sectors of economy as well as in the production chain of civil construction [5].

Despite the benefits to the environment, the use of 
recycled materials can not represent a compromise in efficiency of construction systems. Thereby, the maintenance of the characteristics of flooring systems over time is an important factor for obtaining a product with adequate performance over the time of use [6]. Materials that are very compressible, although promote a high damping of the energy produced by the impact between solids, can lead to excessive reduction in thickness of the material when subject to certain loads, which could cause an increase in dynamic stiffness and the subsequent decrease in attenuation of impact sound.

This relationship between reducing the thickness of the resilient material due to compression over time and estimating the acoustic performance of flooring systems has been studied in several researches [7-9], in which the determination of dynamic stiffness, compressive creep, and the reduction in impact noise provide data for more complete studies.

Therefore, this work presents the mechanical, morphological and physical characterization of layered composites containing residues of PU and PVC skin. The residues are incorporated into the resilient layer of the flooring, through a plate of compressed and particulate polymers to be added below the floor covering.

\section{Materials and Methods}

The procedures adopted involve studies of two layers separately and the final composite with the layers consolidated. A plate has been developed containing a resilient layer (spring of the system) of polymeric residues, and above that a rigid layer (mass of the system) of mortar. This system is placed over the slab forming the flooring system.

\subsection{Characterization of Polymeric Residues}

The PU skin and the PVC were provided by industries that produce foam and furniture in southern Brazil. PU skin residue was ground in a knives mill MARCONI MAS580 ${ }^{\circledR}$ during $30 \mathrm{~min}$ and after that, it was performed a particle size analysis through the vibratory sifter PRODUTEST ${ }^{\circledR}$, following Brazilian Standard NBR 7211 [10], PVC was ground in the knives mill until reaching the size of $\pm 3 \mathrm{~mm}$ for $1 \mathrm{~mm}$.

The PU skin specific mass test was performed according to NBR NM 53 [11], and the PVC specific mass was conducted by the method of NBR NM 52 [12]. In both assays, the polymers floated when immersed, in this way an adjustment was made so that both could stay submerged. It was replaced water for kerosene in the assay, so that the density of the polymers is greater than that of the chosen fluid, and thus it can be submerged. The unit mass test of both polymers was performed according to NBR NM 45 [13].

\subsection{Obtaining the Polymeric Matrix}

It was prepared samples from the polymeric matrix with two dimensions and two different thicknesses. Table 1 shows the formulation of the components used to prepare the PU skin and PVC agglomerate, placed in the resilient layer of the floating floor.

The elastan, tin octanoate, water, PU skin and PVC residues were mixed in an electromechanical beater PAVITEST $^{\circledR}$ for $3 \mathrm{~min}$. After the homogenization, the mixture was dropped in a press ELETRON ${ }^{\circledR}$, into 200 $\times 200 \times 20 \mathrm{~mm}$ molds, submitted to $15 \mathrm{t}$ of pressure, at $40{ }^{\circ} \mathrm{C}$ for $10 \mathrm{~min}$ and $20 \mathrm{~min}$, for $10 \mathrm{~mm}$ and $20 \mathrm{~mm}$ thickness samples, respectively. Fig. 1 illustrates the developed system.

Subsequently, plates were prepared with $1.0 \mathrm{~m} \times$ $1.20 \mathrm{~m}$, also with thicknesses of $10 \mathrm{~mm}$ and $20 \mathrm{~mm}$, keeping the bulk proportion of the material. Above these

Table 1 Composition of agglomerated plates with different thicknesses.

\begin{tabular}{llllll}
\hline Resilient layer $(\mathrm{mm})$ & PU Skin $(\mathrm{g})$ & PVC $(\mathrm{g})$ & Elastan $(\mathrm{g})$ & Tin octanoate $(\mathrm{g})$ & Water $(\mathrm{g})$ \\
\hline 10 & 168 & 42 & 30 & 0.3 & 0.3 \\
20 & 336 & 84 & 60 & 0.6 & 0.6 \\
\hline
\end{tabular}




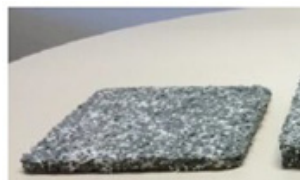

(a)

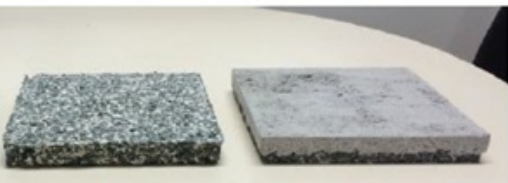

(b) (c)
Fig. 1 Polymeric matrix with thickness: (a) $1 \mathrm{~cm}$; (b) $2 \mathrm{~cm}$; (c) with the cement layer.

plates a cement layer with 40-mm thickness was deposited. The plates with larger dimensions were later used in impact noise tests according to ISO (International Organization for Standardization) 140-7 [14].

\subsection{Obtaining the Subfloor for Impact Noise Test}

For the mortar layer (subfloor), it was used CP IV cement from Votorantim brand, and natural sand as fine aggregate. The sand was dried in a furnace at $100{ }^{\circ} \mathrm{C}$ and packed in a closed plastic box until used in the samples molding. It was used water from the public supplier of Caxias do Sul City. The mortar was molded with a proportion of 1:4 (agglomerate: aggregate) in volume, corresponding to $1: 6.5$ in weight.

\section{Polymeric Matrix Characterization Assays}

Water absorption, void ratio and bulk density tests of the polymeric matrix, were performed following NBR 9778 [15]. The samples were kept in a furnace QUIMIS $^{\circledR}$ in a temperature of $60{ }^{\circ} \mathrm{C}\left( \pm 5^{\circ} \mathrm{C}\right)$ for $72 \mathrm{~h}$. After drying, the samples were kept submerged in water in a room with $23{ }^{\circ} \mathrm{C}\left( \pm 2{ }^{\circ} \mathrm{C}\right)$, they were weighted until reaching mass constancy.

\subsection{Obtaining Samples for SEM}

For SEM assay, it was performed tests in mortar samples with replacement of natural aggregate by the polymer, so that it was possible to know the interaction between the polymer particles and cement crystals. The proportion used to prepare the samples to morphological analysis was 1:4 in volume and 1:6.4 in mass. The materials were homogenized in a melting pot, the mixture obtained was placed in molds with dimensions of $10 \times 10 \times 5 \mathrm{~mm}$ and the SEM analysis were performed in a microscope JSM-5800 model.

\subsection{Determination of Compressive Creep Test}

The compressive creep test was performed following ISO 20392 [16]. The polymeric matrixes of $200 \mathrm{~mm} \times$ $200 \mathrm{~mm}, 10 \mathrm{~mm}$ and $20 \mathrm{~mm}$ thickness were submitted to a constant compression of $200 \mathrm{~kg} / \mathrm{m}^{2}$, and the compressive creep results were quantified after the partial deformation values have been stabilized. The displacements were measured using analogic comparators clocks with $0.01 \mathrm{~mm}$ of precision. The estimated deformation for 13 years of use was determined by regression analysis of the collected data.

\subsection{Dynamic Stiffness Test}

The dynamic stiffness test was performed according to ISO 9052 [17]. Thus, a shaker L315M-ETS model was used to cause vertical vibration, with sinusoidal signal and constant acceleration. The principle of this assay is the determination of apparent dynamic stiffness $\left(s^{\prime}\right)$ of the sample through the resonant frequency of the resilient material used as a spring in the mass-spring-mass system. The signs of strength and acceleration were checked by two accelerometers 3035B2-DYTRAN ${ }^{\circledR}$, being one coupled to the base below the sample, and the other on the load plate placed over the sample.

Through the test with the samples of $200 \times 200 \mathrm{~mm}$, $10 \mathrm{~mm}$ and $20 \mathrm{~mm}$ thickness, it was found the resonance frequency of the elastic base, with its dynamic stiffness calculated according to Eq. (1):

$$
s^{\prime}=m^{\prime}\left(2 \pi f_{0}\right)^{2}
$$

where, $s^{\prime}=$ dynamic stiffness of the resilient layer $\left(\mathrm{MN} / \mathrm{m}^{3}\right), m^{\prime}=$ mass per unit area $\left(\mathrm{kg} / \mathrm{m}^{2}\right), f_{0}=$ resonance frequency $(\mathrm{Hz})$.

The real system resonance frequency was calculated according to Eq. (2):

$$
f_{0}=\frac{1}{2 \pi} \sqrt{\frac{s^{\prime}}{m^{\prime}}}
$$


From the results of the performed tests, it was estimated the impact noise reduction for each of the samples. Through Eq. (3), it is possible to estimate the reduction in sound pressure level of the percussion noises, $\Delta L(\mathrm{~dB})$ in floating floors:

$$
\Delta L=30 \log \left(\frac{s^{\prime}}{m^{\prime}}\right)
$$

The results mean the reduction of the sound level applying a resilient layer beneath a rigid plate, with a surface density of $2,340 \mathrm{~kg} / \mathrm{m}^{2}$.

To reduce sound pressure level of the weighted impact, EN 12354-2 presents an abacus in which there is the weighted value from the dynamic stiffness of the resilient layer and the surface density of the subfloor.

\subsection{Impact Noise Test}

Impact noise test was performed according to ISO 140-7 [14], using a Bruel \& Kjaer 2270 analyzer and a Bruel \& Kjaer 3207 impacts machine. Impact noise was generated in the emission room, on the floor just above the reception room, and measured in five different positions in third octave bands in the frequency range from $100 \mathrm{~Hz}$ to $3,150 \mathrm{~Hz}$.

The rooms are separated by a structural concrete slab $13 \mathrm{~cm}$ thickness and are composed by masonry walls of ceramic blocks $14 \mathrm{~cm}$ thickness, coated with plastering mortar. The room dimensions are $2.55 \times 4.96 \times 2.58 \mathrm{~m}$, with a total area of $12.64 \mathrm{~m}^{2}$ and a volume of $32.63 \mathrm{~m}^{3}$. Fig. 2 shows an illustrative scheme of the assay.

The analyzed samples were $1.20 \times 1.00 \mathrm{~m}$, molded in situ. It was opted for the reduced size samples in order to reduce the generation of waste from the research itself and optimize the time in this phase of the study, as weighted by Miškinis et al. [18].

Thus, the results are valid for acoustic performance comparisons between different thicknesses, and can reveal the influence of polymeric residues in the acoustic insulation of floors. Fig. 3 shows the samples for the impact sound test.

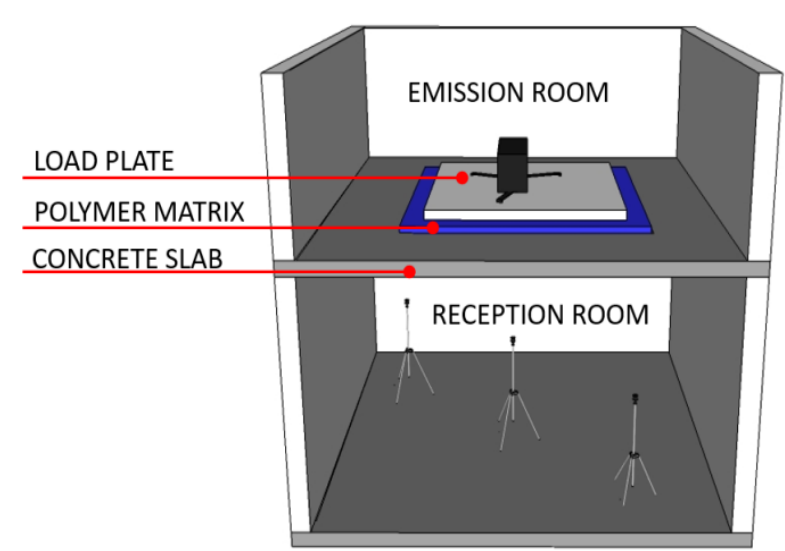

Fig. 2 Illustrative scheme of the overlapping emission and reception rooms, for impact noise test.

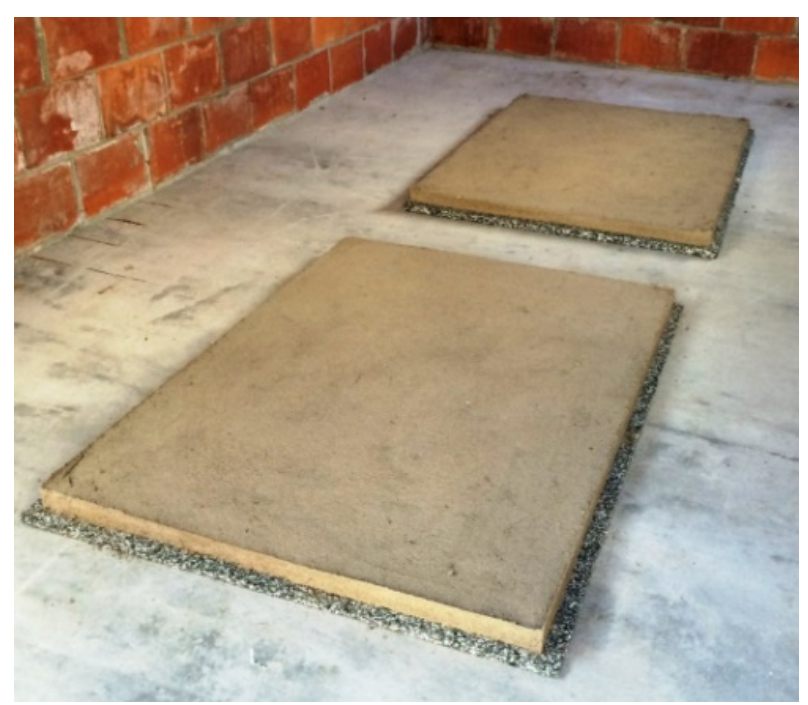

Fig. 3 Samples for the impact noise tests.

\section{Results and Discussions}

\subsection{General Characteristics of the Polymers}

The average particle size of the PU skin was $4.75 \mathrm{~mm}$, classified as granular solids. The format of the PVC residue are strips. The unit mass of the PU skin and PVC residues are respectively $965 \mathrm{~kg} / \mathrm{m}^{3}$ and $926 \mathrm{~kg} / \mathrm{m}^{3}$. The PU skin and PVC specific mass are $942 \mathrm{~kg} / \mathrm{m}^{3}$ and $914 \mathrm{~kg} / \mathrm{m}^{3}$. The PU skin residue showed higher unitary and specific mass values.

The specific mass of a material is influenced by its porosity. In addition to the porosity, size and shape distributions of the grains influence unit mass. To dosage effects, it is necessary to know the space occupied by the aggregate particles, including pores 
within the particles. Thus, the density values of PU and PVC skin were evaluated factors in the proportions of the polymer matrix composition.

\subsection{General Characteristics of the Polymeric Matrix}

In porous materials, the sound damping is primarily related to the dissipation of energy due to air friction during propagation through the pores and, also, by viscosity and internal friction when the vibration occurs from the very structure of the material [19]. The amount of voids is directly proportional to the mechanical impact damping. However, this data should be analyzed along with other characteristics, because sound insulation materials of floors should also offer stability and little deformation over time of use.

The bulk densities values of the residues plate (Table 2) can be translated into lighter construction systems and less structural wear of the building, and therefore reduced structural elements.

\subsection{Cementitious Matrix Characteristics}

The cementitious matrix presented compression strength values of $22.2 \mathrm{MPa}$. The tensile strength value in the mortar flexion was $4.8 \mathrm{MPa}$.

\subsection{SEM}

It was observed in Fig. 4a a physical shoring between the cement crystals and the PU skin, and a surface permeability. The physical shoring works optimally reducing the vibrational response in the surface, forming the spring-mass system. If there was an overall permeability, forming a transition interface, there would be a stiffening of the resilient material, which works on damping and impact noise insulation. In Fig. 4b, it is possible to see that the PVC does not interact directly with the mortar, because its function is to ensure the integrity of the polymeric matrix conferring a mooring substituir virgulas por pontos between the PU skin particles and a dispersion of the mechanical impact to the PU skin.

\subsection{Compressive Creep}

The polymeric matrix is constantly compressed over time, simulating an actual situation of use of 13 years, which corresponds to the required lifespan for flooring systems in Brazil, and causing a deformation that reduces its void ratio. Thus, it is aimed the smaller possible deformation that keeps the damping property, influenced by polymers' voids. The matrix of $10 \mathrm{~mm}$ deformed on average $5.9 \%$ of its thickness, while the matrix with $20 \mathrm{~mm}$ deformed $2.3 \%$ of its thickness.

It is possible also to compare the results with the compressive creep deformation of resilient materials commonly used in impact noise reduction in floors. Gnip et al. [7] analyzed the deformation by constant compression in samples with seven different thicknesses and densities of mineral wool and the deformation was lass in thin samples than in the thicker, without presenting a linear ratio results.

These values represent a low deformation in the samples thickness, and consequently a little change of its properties over the lifespan of the system. Thus, it can be considered that the studied materials will not reduce its capacity of impact noise insulation in function of the thickness reduction resulting from compression during the building time of use.

\subsection{Dynamic Stiffness}

Table 3 presents the results of resonance frequency $\left(f_{0}\right)$ and dynamic stiffness $\left(s^{\prime}\right)$ of the samples with $10 \mathrm{~mm}$ and $20 \mathrm{~mm}$ thickness.

The thickness of the samples presents an inversely proportional relationship with the dynamic stiffness of the material. Thus, the required thickness of the

Table 2 Resonance frequency and dynamic stiffness results.

\begin{tabular}{llllll}
\hline $\begin{array}{l}\text { Resilient matrix thickness } \\
(\mathrm{mm})\end{array}$ & $\begin{array}{l}\text { Water absorption } \\
(\%)\end{array}$ & $\begin{array}{l}\text { Void ratio } \\
(\%)\end{array}$ & $\begin{array}{l}\text { Bulk density } \\
\left(\mathrm{kg} / \mathrm{m}^{3}\right)\end{array}$ & $\begin{array}{l}f_{0} \\
(\mathrm{~Hz})\end{array}$ & $\begin{array}{l}s^{\prime} \\
\left(\mathrm{MN} / \mathrm{m}^{3}\right)\end{array}$ \\
\hline 10 & 98.22 & 58 & 540 & 42.43 & 14.07 \\
20 & 94.3 & 55 & 562 & 33.53 & 8.79 \\
\hline
\end{tabular}




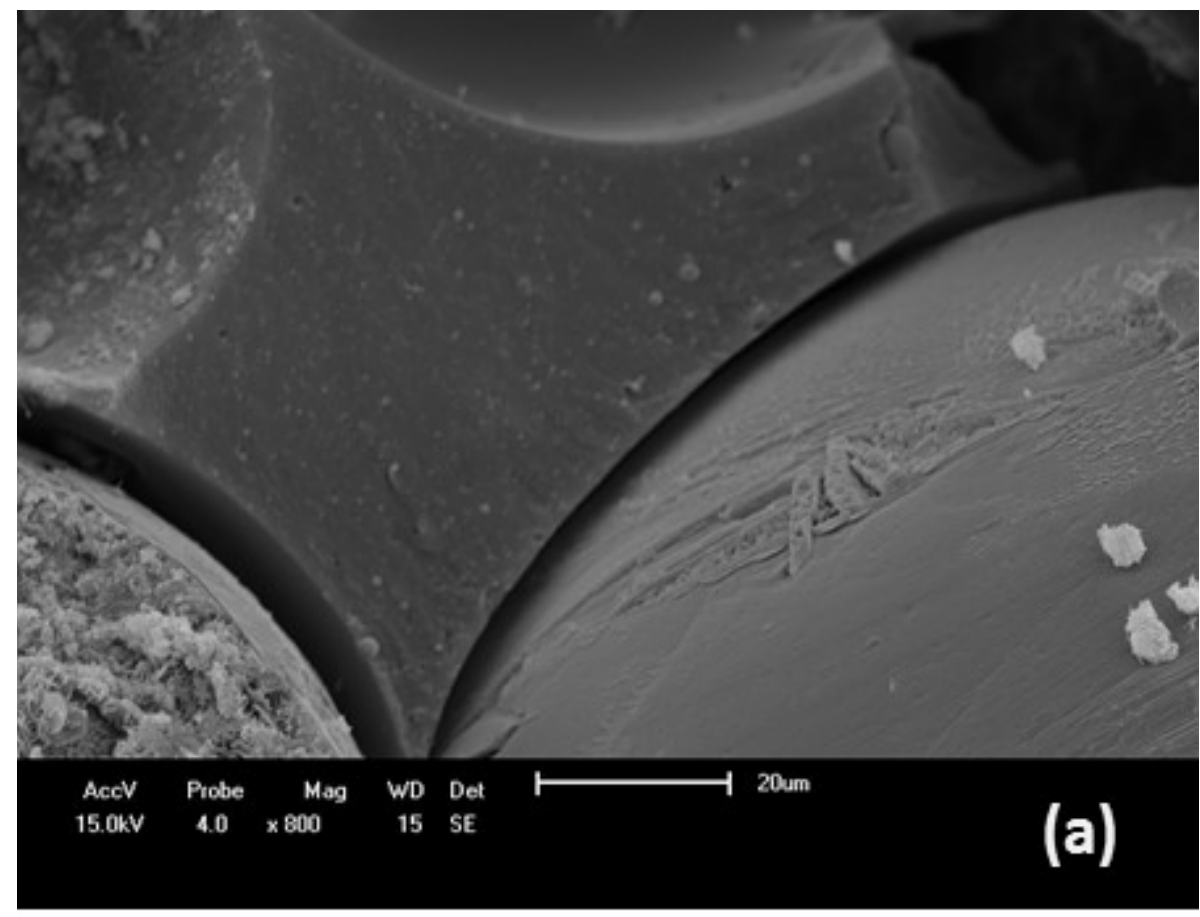

(a)

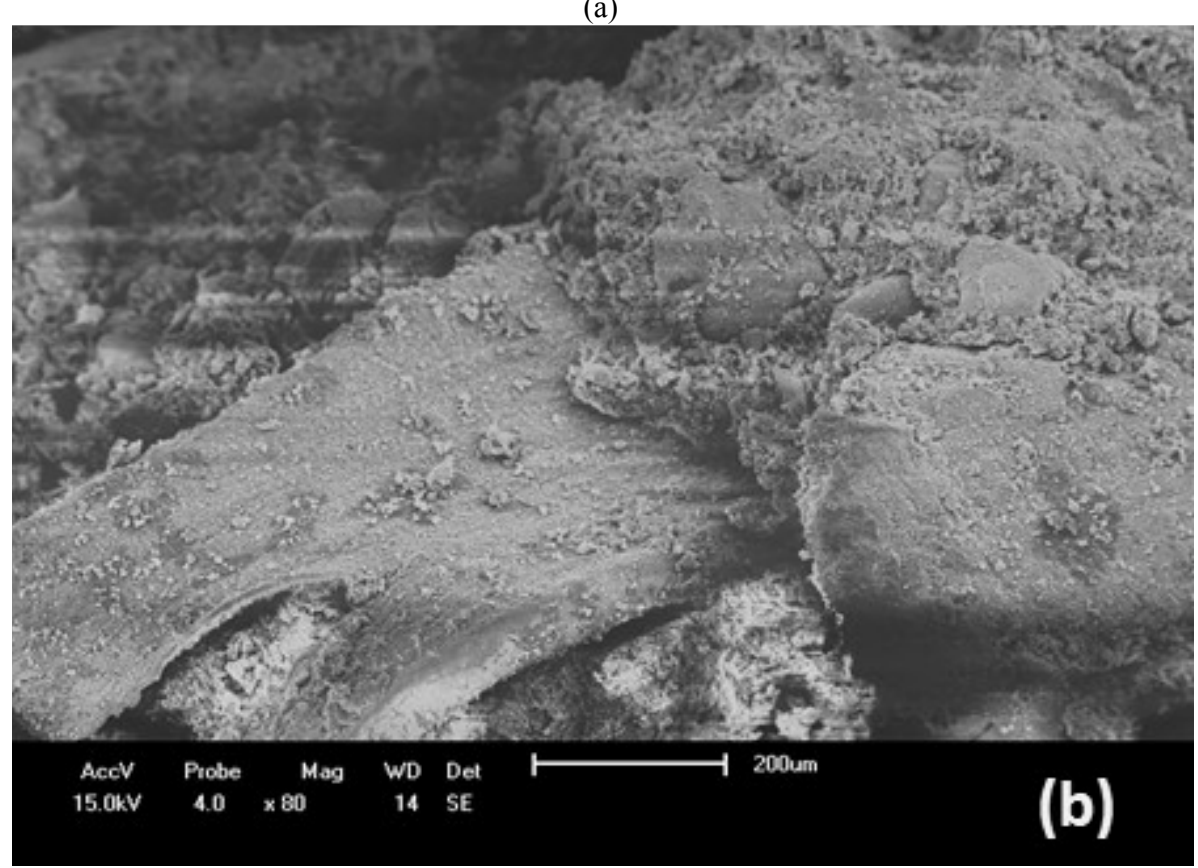

(b)

Fig. 4 SEM micrograph of cementitious samples with PU skin and PVC residues: (a) physical shoring between the cement crystals and the PU skin; (b) lack of connection between PVC and mortar.

subfloor, considering the same sound reduction index, also follows the same logic, but not linearly.

The increased thickness of the subfloor represents an enhance in the load of the whole building structure, thus impacting the design of foundations, because lower thicknesses in heavy systems are most feasible in civil construction.

Considering this relationship and the usual thickness of subfloor with conventional mortar, between $3 \mathrm{~cm}$ and $5 \mathrm{~cm}$, and its apparent mass density of $2,340 \mathrm{~kg} / \mathrm{m}^{3}$, 
the resilient layer of the studied material of $10 \mathrm{~mm}$ already reached an efficient impact noise insulation, for current Brazilian standards.

If 20-mm matrix is used, the efficiency of insulation will increase for the same thickness of subfloor. The use of the resilient layer of $20 \mathrm{~mm}$ theoretically leads to a reduction of surface mass of the subfloor, however, reduced thicknesses of mortar, in practice, are not performed in buildings.

For a spring-mass system with a $10 \mathrm{~mm}$ polymeric matrix and a 4-cm subfloor, the reduction of impact noise is estimated at $29 \mathrm{~dB}$. For the same subfloor thickness but a resilient layer of $20 \mathrm{~mm}$, it is calculated a reduction of $32 \mathrm{~dB}$. Estimating a polymeric layer of $30 \mathrm{~mm}$, and the same $4 \mathrm{~cm}$ thickness of subfloor, the system can provide a reduction of $35 \mathrm{~dB}$. These results were obtained using the parameters from standard EN 12354-2 [20].

Currently, it is admitted levels of $L_{n, w}$ of $80 \mathrm{~dB}$ for concrete slabs of $10 \mathrm{~cm}$, with acoustic performance classified as minimum according to Brazilian standard. The application of floating floor system can result in values of impact noise levels between $45 \mathrm{~dB}$ and $51 \mathrm{~dB}$, which is, according to the standard NBR 15575 [21], an acoustic performance with a higher level.

\subsection{Impact Noise}

The results of impact noise test showed a level of impact noise of $79 \mathrm{~dB}$ to a $13-\mathrm{cm}$ slab thickness, without the application of floating floor.

With the installation of floating floor system, through the $10-\mathrm{mm}$ resilient matrix and a mortar layer of $4 \mathrm{~cm}$, it was measured a level of impact noise of $59 \mathrm{~dB}$. For the $20-\mathrm{mm}$ resilient material and $4-\mathrm{cm}$ mortar layer, it was measured a level of impact noise of $58 \mathrm{~dB}$.

The values of theoretical calculations made earlier in the dynamic stiffness test showed more favorable results. Through theoretical model, it was obtained an impact noise reduction value $(\Delta L)$ of $29 \mathrm{~dB}$ for the 10 -mm polymeric matrix, and $32 \mathrm{~dB}$ to $20 \mathrm{~mm}$ thick.
Therefore, it resulted in an insulation of $50 \mathrm{~dB}$ and $47 \mathrm{~dB}$, respectively, for floor system having the structural slab with $13 \mathrm{~cm}$. The reason lies in the fact that the theoretical parameters used to define these values by EN 12354-2 [20] assume a floor system with infinite dimensions, but the impact noise test was carried out through samples of $1.20 \times 1.00 \mathrm{~m}$.

The resilient material layer serves to dissipate the vibration, but variations in the dimensions of a sample carry different results for the same material tested. Miškinis et al. [18] showed that when the sample is too small, the dissipation changes and affects the value of impact noise insulation.

It was concluded in their study that the size of the sample has significant influence on results. It was shown that samples (smaller than $10 \mathrm{~m}^{2}$ ) can be used to determine $\Delta L_{W}$, but values must be corrected using derived equations. According to the test results, the influence of the tested area can represent more than $11 \mathrm{~dB}$ for the weighted reduction in impact sound pressure level. Through it, it is possible to establish a closer relationship between the theoretical and practical values.

Working with $L_{n, w}$ values closer to reality, it can be seen that the difference found between the materials of different thickness of 10 and $20 \mathrm{~mm}$ is small when considered the manufacturing process of each thickness and proportions of materials involved in the process. Results are already favorable to the $10 \mathrm{~mm}$ thick polymeric matrix, considering that are smaller than the maximum value established by the standard, which is $80 \mathrm{~dB}$, conferring a higher acoustic comfort to the environment through damping the impact noise.

\section{Conclusions}

This study aims to develop resilient materials with polymeric residues, working in a mass-spring-mass system of floating floors. An important aspect when working with residues in construction industry, is the life of the material, because a product that has short 
durability leads to generation of new solid waste, often difficult to degrade.

The compressive creep test showed a satisfactory life span expectancy, since compression over time showed a low percentage of deformation of the material, maintaining its characteristic of damping the impact noise. The ability that resilient material has to absorb the impact can be assessed by their dynamic stiffness. From the determination in the laboratory, the dynamic stiffness of materials and the test results, it was possible to forecast the reduction of impact noise that these materials provide.

The morphology of SEM samples presented a physical shoring between the mortar and the residue PU skin, showing the mass-spring-mass system, which operates in insulation from the noise propagated by the structure. The voids ratio presented by the polymeric matrix contributes to the sound damping, so that the noises between autonomous units are reduced.

Impact noise insulation test showed that it is possible to observe the reduction of impact noise level that passes through the slab, leading to values compatible with the theoretically estimated through the dynamic stiffness, when evaluating the issue of small sample sizes.

Furthermore, it is possible to observe that a resilient matrix of PU skin and PVC with $10 \mathrm{~mm}$ thickness and a $4 \mathrm{~cm}$ subfloor has a satisfactory level of efficiency, thus leading to an economic raw material processing economy in manufacturing polymeric matrix.

\section{Acknowledgments}

This work was funded by University of Caxias do Sul, through the research group of lightweight concrete. Additional support was provided by CNPq (National Council of Scientific and Technological Development), FAPERGS (Research Support Foundation of Rio Grande do Sul State) and Basf of Brazil Ltda.

\section{References}

[1] Damineli, B. L., Kemeid, F. M., Aguiar, P. S., and John, V. M. 2010. "Measuring the Eco-efficiency of Cement Use." Cem. Concr. Compos. 32: 555-62. doi:10.1016/j.cemconcomp.2010.07.009.

[2] Yu, C. J., and Kang, J. 2009 "Environmental Impact of Acoustic Materials in Residential Buildings." Build. Environ. 44: 2166-75. doi:10.1016/j.buildenv.2009.03.013.

[3] Tutikian, B. F., Nunes, M. F. O., Leal, L. C., and Marquetto, L. 2013. "Hormigón Ligero con Agregado Reciclado de EVA para Atenuación del Ruido de Impacto, Mater." Construcción 63: 309-16. doi:10.3989/mc.2012.06911. (in Portuguese)

[4] Alessandro, F. D., Asdrubali, F., and Baldinelli, G. 2014. "Multi-parametric Characterization of a Sustainable Lightweight Concrete Containing Polymers Derived from Electric Wires." Constr. Build. Mater. 68: 277-84. doi:10.1016/j.conbuildmat.2014.06.075.

[5] Gupta, V. K., and Khakhar, D. V. 1999. "Formation of Integral Skin Polyurethane Foams." Polym. Eng. Sci. 39: 164-76. doi:10.1002/pen.11405.

[6] Meyer, C. 2009. "The Greening of the Concrete Industry." Cem. Concr. Compos. 31: 601-5. doi:10.1016/j.cemconcomp.2008.12.010.

[7] Gnip, S. V., and Vejelis, S. 2013 "An Estimated Prediction of the Deformability of MW (Ineral Wool) Slabs under Long-Term Compressive Stress." Constr. Build. Mater. 38: 675-80. doi:10.1016/j.conbuildmat. 2012.07.043.

[8] Schiavi, A. P., Belli, M. C., and Russo, F. 2007. "Acoustical Performance Characterization of Resilient Materials Used under Floating Floors in Dwellings." Acta Acust. United with Acust. 93: 477-85.

[9] Kim, K. W., Yeon, J. O., Yang K. S. and Kim, M. J. 2015. "Influence of Loading Time of a Load Plate and Sample Size on the Measurement of Physical Properties of Resilient Materials." Arch. Acoust. 40: 159-67. doi:10.1515/aoa-2015-0018.

[10] ABNT (Brazilian Association of Technical Standards). 2009. Aggregates for Concrete-Specification. Rio de Janeiro: ABNT. (in Portuguese)

[11] ABNT. 2009. Coarse Aggregate-Determination of Density, Apparent Density and Water Absorption. Rio de Janeiro: ABNT. (in Portuguese)

[12] ABNT. 2009. Fine Aggregate-Determination of Density and Bulk Density. Rio de Janeiro: ABNT.

[13] ABNT. 2006. Agregados-Determinação da Massa Unitária e do Volume de Vazios. Rio de Janeiro: ABNT. (in Portuguese)

[14] ISO (International Organization for Standardization). 1998. ISO 140-7: Acoustics-Measurement of Sound 
Insulation in Building Elements-Part 7: Field Measurements of Impact Sound Insulation of Floors. Geneva: ISO.

[15] ABNT. 2005. Mortar and Concrete Cured-Determination of Water Absorption, Voids and Densit. Rio de Janeiro: ABNT. (in Portuguese)

[16] ISO. 2007. ISO 20392: Thermal-Insulating Materials-Determination of Compressive Creep. Geneva: ISO.

[17] ISO. 1989. ISO 9052-1: Acoustics-Determination of Dynamic Stiffness. Part 1: Materials Used under Floating Floor in Dwellings. Geneva: ISO.

[18] Miškinis, K., Dikavičius, V., Ramanauskas, J., and Norvaišienè, R. 2012. "Dependence between Reduction of Weighted Impact Sound Pressure Level and Specimen
Size of Floating Floor Construction.” Mater. Sci. 18: 93-7. doi:10.5755/j01.ms.18.1.1350.

[19] Maderuelo-Sanz, R., Martín-Castizo, M., and Vílchez-Gómez, R. 2011. "The Performance of Resilient Layers Made from Recycled Rubber Fluff for Impact Noise Reduction." Appl. Acoust. 72: 823-8. doi:10.1016/j.apacoust.2011.05.004.

[20] British Standards Institution. 2000. BS EN 12354-2: Building Acoustics-Estimation of Acoustic Performance of Buildings from the Performance of Elementas-Part 2: Impact Sound Insulation between Rooms. London: British Standards Institution.

[21] ABNT. 2013. Residential Buildings-Performance. Part 3: Requirements for the Floors Systems. Rio de Janeiro: ABNT. (in Portuguese) 